\title{
'Towards understanding the nature of history and its limitations': An interview with the American Artist David Schutter
}

\section{Keywords}

David Schutter

painting

collections

repetition

tradition

unrepresentable

mimesis

meta-historical mode

\section{Abstract}

In this conversation American painter David Schutter and the author discuss key aspects of Schutter's work. 1. Schutter (born 1974), whose work makes reference to major European painting collections, explores in his 2. work the relation to tradition and repetition of artistic conventions. His work, presented at Documenta 143. (2017), often employs strategies of radical limitation of the colour scheme, and restriction of visibility, some- 4. times blackening out the image plane altogether. This raises questions about the detachment from the referent 5 . object, self-reflexivity and the trope of unrepresentable in contemporary painting in the beginning of the 6 . twenty-first century. The conversation will further focus on ways Schutter's work transgresses from a narrow 7. mimetic framework by mitigating in his paintings the difference between original and double and by employ- 8 . ing diminished clarity and ambiguity in his work. 
1. In his work American painter David Schutter (born 1974) follows a classical Platonic model. Dealing 2. with aspects of distancing and doubling, the titles of his exhibitions, including 'after paintings', 3. 'repertory' and 'rehearsal', suggest the idea of staging or mediation, where the images, as shadowy . simulacra, never come close to the 'ideal' form. By unravelling the complex relationships between the original, the source, and the artistic rendering, Schutter's work debunks traditional assumptions of immediacy and visibility of images. The need for distance and detachment, reflects, in Rancière's words, a'revivification' of the Platonic model, when he argues:

The spectator must be removed from the position of observer calmly examining the spectacle offered to her. She must be disposed of this illusory mastery, drawn into the magic circle of the theatrical action [...] For one, the spectator must be allowed some distance; for the other, he must forego any distance. For one, he must refine his gaze, while for the other, he must abdicate the very position of viewer.

(2009: 4)

16. The paradoxical relationship between distance and proximity, visibility and blindness, applies to 17. Schutter's practice, as illustrated in two of his most recent paintings shown at Documenta 14 (Kassel,

18. 2017). Despite the intense study of the Renaissance painter Parentino at the collection at the Galleria

19. Doria Pamphilj in Rome, the paintings do not allow an immediate recognition of the source

20. (see Figure 1). Instead of following the mimetic model, the paintings 'act as deposits of the artist's 21. memory of having spent long days just looking at two works' (Roelstraete 2017). ${ }^{2}$ Whether one inter-

22. prets these references as 'homage or annihilation' of historic collections ${ }^{3}$ (Halvorson 2014), Schutter's

23. paintings can be seen as a 'referent object' that indicates the historical and institutional context as

24. well as artistic intentions. As he explains in relation to his most recent work shown at Documenta 14:

25. 'I consider the value of surface information: that it can accrue into a forensic investigation, and give

26. over to the more phenomenal aspects of seeing' (Roelstraete 2017). And yet, despite this apparent

27. proximity of his work to the 'original' piece, Schutter's paintings deliberately stretch the idea of

28. subject matter and legibility, where the obfuscated paintings allow only limited access to the original

29. image source. ${ }^{4}$ The work clearly does not intend to produce copies made after the originals; the paint-

30. ings are, as he argues, 'a gesture toward understanding the nature of history and its limitations'

31. (Schutter 2007)

32. The return to the past (and references to historic archives, ranging from fifteenth-nineteenth-

33. century western European painting collections) and the notion of distance is prevalent in Schutter's

34. work and can be seen as part of a broader tendency in contemporary art in the last decade. Coined

35. as 'meta-historical mode', artistic practices show a particular interest in reenacting and recon-

36. structing the past as 'another type of storytelling', avoiding to 'look at the present' (Roelstraete
1. The title is taken from a statement David Schutter made in 2007 after his residency in Berlin, working on the cycle 'After Paintings' which is linked to the painting collection at the Gemäldegalerie, Staatliche Museen zu Berlin.

2. Schutter's work has frequently been interpreted as dealing with aspects of distance and past showing for example sthewing for exampl the perceptible archaeology of art objects' (Halvorson 2014); 'Rather than a nihilistic endgame or a refutation of history, Schutter crafts memento mori to capture the distance between what was and what is' (Elms 2007: 59).

3. Schutter makes in his work both reference to specific painting to specific painting collections as well as the display an arrangements of these collections (see e.g. Constable's cloud paintings in the Yale Centre for British Art [2008] to the most recent work referencing the Gurlitt Estate and Gurlitt Estate and Max Lieberman, shown the 'Documenta 14 ' [2017]).

4. Schutter's paintings have been described 

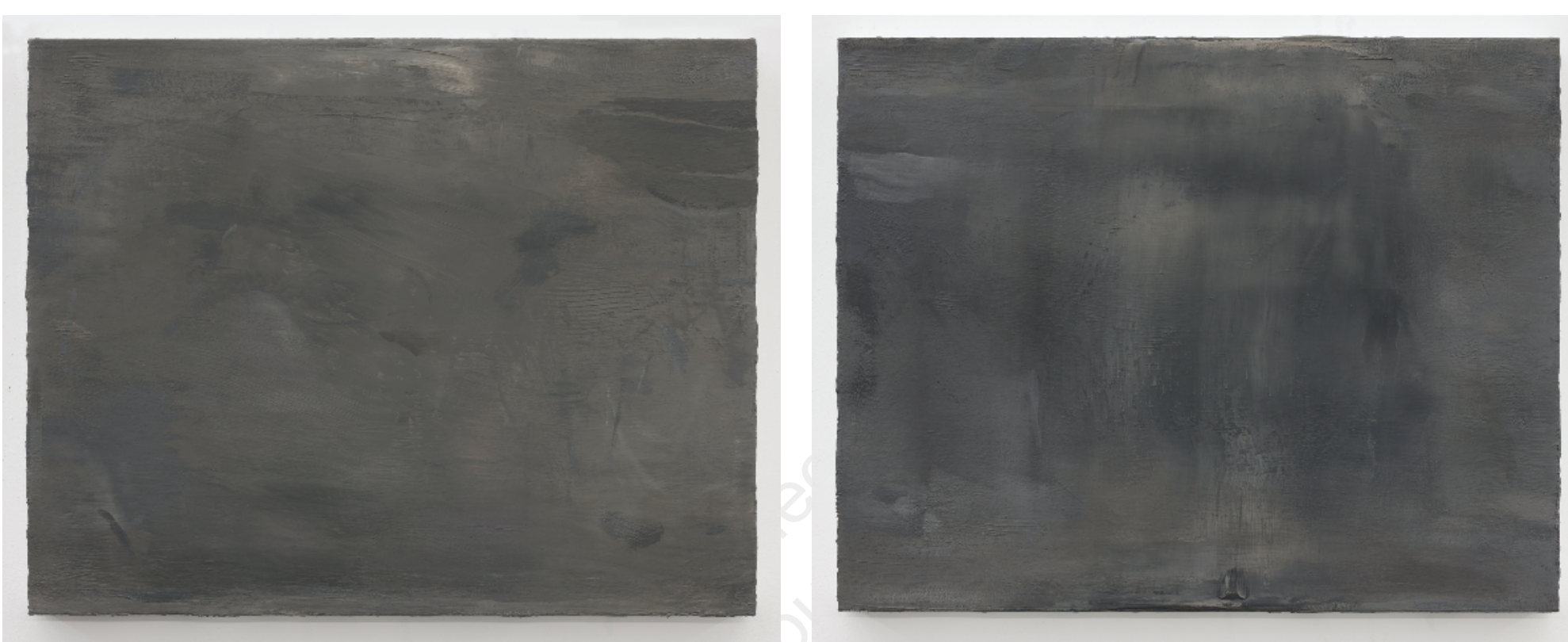

1.

2.

3.

4.

6.

7.

8.

9

10.

11.

12.

13.

14.

15.

16.

17.

18.

19.

20.

21.

Figure 1: David Schutter (2017), DP P 587 PR, DP 588 PR, (Two paintings, oil on linen, $46 \times 58.5$ cm each), Image Credit: James Prinz. 
1. 2009). ${ }^{5}$ Indeed, David Schutter's obfuscated image planes create a sense of detachment, yet never

2. totally eliminate references to the image source. The distance between copy and original is further 3. emphasized in his attempt to eschew the direct confrontation with the latter in order to avoid 4. what he describes as the 'always already there quality' of the museum's display. The work, after a 5. period of intense consultation (a concentrated 'phenomenological' study of the work without any devices or aids), progresses without accessing the original piece, allows him to 'restore [...] mean. $\quad$ ing from the traditional and institutional metaphors already set firmly in place' (Schutter 2007). ${ }^{6}$

8. The aspect of distancing can be also read as his way of dealing with artistic tradition and past in 9. general.

10. Bryson has explored the complexities of artistic practice and its relation to tradition in his discus11. sion of French neo-classicist painting. Tradition and the repetition of conventions confront the artist

12. with one of the main struggles in contemporary art. The painter's constant conflict with the presence

13. of the past is a 'negotiation with repetition': 'If a painter fails in his fight against repetition', Bryson

14. adds, 'presence will elude his image, and tradition will expropriate or annex his work' (1984: 28).

15. With its close references to specific painting collections Schutter's work, however, seems to reflect

16. this struggle, this searching for a direct juxtaposition between the 'model', the source material or 17. reference point, and his artistic rendering.

18. Schutter's paintings, then, display, in his own words, 'the liminal traces after a struggle' (2007). In 19. his conceptualization of the Mystic writing pad Freud explained how the material leaves a faint, but

20. perceptible trace on the waxen surface below, a trace which can be seen if one were to lift up the

21. sheet of plastic and examine the wax surface. Schutter's work leaves the viewer and the painter in a

22. situation where the plastic sheet has been lifted. The viewer is thus left with the traces of a work that

23. appears uncoupled from direct accessibility. It may seem that Schutter's obfuscated image surfaces

24. wish to eliminate any references to the original. Yet, just like Freud's mystic writing pad, traces reveal

25. a broader understanding of appearance and disappearance. ${ }^{7}$

26. Indeed, in recent years painters have shown a particular interest in diminishing the clarity of the

27. image. There is a fascination with ambiguity, with the dissolution of images (see e.g. Maaike Schoorel,

28. Silke Otto-Knapp, Chris Ofili, Idris Khan and others). Seen as an attempt to disconnect the image

29. from a narrow mimetic framework, these new negations of representation have been justified as an

30. attempt to deviate from heteronormative readings and to widen art historical discourses (see, e.g.,

31. Kaneda [1991 or Enwezor [2008]).

32. As Schutter unpacks this point in our conversation:

33.

I am not intentionally cultivating obfuscation, nor am I interested in a baffling of the eyes of the beholder. I am interested in deadpan presentation and the events that follow. To me, the presentation of illusory space is a parlour trick that questions belief structures. I consider my as 'leading to a kind of foggy confusion of the alternatively of the alternatively fully recalled, half remembered, and misremembered details represented (Molon 2007).

5. The 'meta historical mode', also referred to as a 'retrospective' or 'historiographic mode', identifies a particular strand in recent contemporary practices that shows an increased interest an increased interest in reconstruction and reenactment of archival material (Roelstraete 2009: 1). The practices, dealing with the complex relationships within the archive and memory, purposefully endorse an overlap of timeframes,

instances illegibility or a certain 'resistance' a certain 'resistance' resulting in alternative or unorthodox readings. Schutter's investment in archives and exploration of the past is further highlighted through highlighted through his participation of the 2013 exhibition 'The Way of the Shovel: On the Archaeological Imaginary in Art' (November 9 2013March 92014 Museum of Contemporary Art Chicago, curated by Chicago, curated by The exhibition 
investigates the role of the historical, archival research in contemporary atis contemporary artistic practices (see also

Schutter elaborates

on the paradoxical

point of proximity and distance:

As an example of

as basic exis

ic existential problem, a museum painting's 'always already there quality' forced me to the task of contesting the original work of art, in the hope that I could restore for myself meaning myself meaning from the tradition and institutional metaphors already set firmly in place.

7. The 'mnemonic

potential' of painting as Gingeras (2005) argues, shows a

particular focus on the materiality of painting. The arguable 'sensuality' of painting is defined, unlike photography, as a way the viewer responds to the materiality of painting and its potential to trigger personal recollections. I wish to suggest, since the relationship between painting and photography is paintings and drawings to be illusory works in the conventional sense. However, as you say, 'not being able to see' is important in this regard.

To some extent we may interpret the obfuscation of the image plane as allowing not only a distancing from any substantive content, but as raising more far-going questions of the unrepresentable. Notwithstanding the wide range of instances of the unrepresentable, from instances of the sublime to iconoclasm, I wish to focus here on the relationship between the'way of making and the economy of affects', concerned with the excess or lack of visibility (Rancière 2007: 112). The scepticism towards the visual regime happens at a time when painting is increasingly exposed to technological progress and phenomena such as the Internet, video, portable devices, CCTV footage or virtual reality. The widening tendency of this hybridization is somewhat countered by the fact that paintings have become more and more 'impenetrable' and show a lack of legibility (Geimer 2012). Schutter's work seems to disentangle the image from the increased media consumption. It encourages viewers to decelerate their perception, while putting a particular focus on the marks and gestures. It stretches the link between trace and its 'organic' referent. Gestures and texture, traditionally seen as a marker of authorship, have been removed from its original context. Instead, distance and detachment could be attributed here to a sort of 'miming' or staging. ${ }^{8}$ In his recent work Spolia (2016) Schutter employs a series of complex strategies: he reuses, reframes and re-contextualizes a selection of'syntaxes and jargons' of his art historical references. The notion of the mark related to an author and personal gesture thus becomes almost irrelevant. Yet, despite the detachment of the sign, and the distancing from the original source, the thread is never cut entirely. ${ }^{9}$

Legibility, or the suspension of the overtness of the sign, as a key aspect in artistic practice becomes crucial to understand Schutter's paintings. His work not only examines the relationship between copy and model (as exemplified in the DP P 587 PR, DP 588 PR [2017] mentioned above) and the idea of resemblance, it also allows a transgression of the narrowing mimetic framework. Mimesis is therefore not understood, as Rancière reminds us and Schutter's work reflects poignantly, as an accurate copy but, rather, as a 'way of making resemblances function within a set of relations between ways of making, modes of speech, forms of visibility and protocols of intelligibility' (Rancière 2007: 73).

The conversation with David Schutter started in person in June 2016, while Schutter was a fellow a the American Academy in Rome and continued over the following months.

Christian Mieves: The titles of some of your past projects suggest the notion of distancing or repetition in your work (e.g. 'repertory', 'rehearsal'; 'repetition'). Does your work suggest, in a linear way, an increasing distancing, detachment, or, is it in fact the opposite, the idea of getting closer? 
1. David Schutter: I don't think of the titles, particularly of Rendition (2013) (in which I remade a 2. suite of four paintings from the Barbizon room of the Art Institute of Chicago) or Repertory (2007) 3. (in which I remade a frieze of ten cloud studies by John Constable situated in the Yale Center for 4. British Art) as distancing. Rather, I think that by framing the language of the exhibition titles in the 5. 're-', distance is implied as only the beginning point of a perspective that can grow forward from 6. that problematic position. The very repetition that I embrace is an invitation to advance toward the 7. object, to see difference, to begin a conversation that is sustainable and therefore to offer a closer . looking at painting.

10. CM: I am very interested in the work process. Your painting deals with the idea of repetition and variation, 11. while diffusing a clear opposition between copy and original. In particular, this seems to reflect a shift in our

12. understanding of representation itself. I am thinking, for example, of your work on Constable's cloud studies.

13. While Constable's work still echoes a 'fidelity' of scientific observation of nature as a 'standard of scale', your

14. work approaches it from a different perspective. Could you elaborate on this?

15.

S: It has been very relevant to me. Constable considered his field studies to be a form of natural science. After all, he went into the field to strengthen his representations of clouds after criticism that . his painted clouds were lacking in depth and were not reflective of natural phenomena (perhaps

19. they were too pictorial and classic against trends favouring a vector from naturalism to the sweep19. ing abstractions of Turner). He sought to form a more real depiction from field observation, but he 20. also took with him into the field a pedagogical manual for depicting clouds, printed for artists by 21. Alexander Cozens. The manual was full of schematics. Constable used both this manual and his
Schutter's work in particular allows a reevaluation of the painterly sign beyo painterly sign beyon its material quality

8. Hochdörfer argues that the "crisis of the subject' coincides with the crisis of contemporary painting (in Ammer et al. 2015: 15). This becomes in particular relevant in Schutter's referencing of painting collections can be understood as "user-based-content' as "userbased-content' as introduced by Am et al. in the 2015 exhibition 'Painting 2.0: Expression in the Information Age'. The exhibition further fosters a critical re-evaluation of the notion of gesture as 'privileged marks as 'privileged marks from the hand' and authorship (Ammer et al. 2015: 10) which I see as one of the key aspects in Schutter's work. For a further discussion of 'Painting 2.0: Expression in the Information Age (Nov 2015-April 2016 (Nov 2015-April 2016, (see Ammer et al. 2015)

9. Yve-Alain Bois argues in Painting as Model that painting has already reached the condition of photography and of photography and
the division of labour is already 'interiorized' in the painter (1993: 231). Painting therefore 


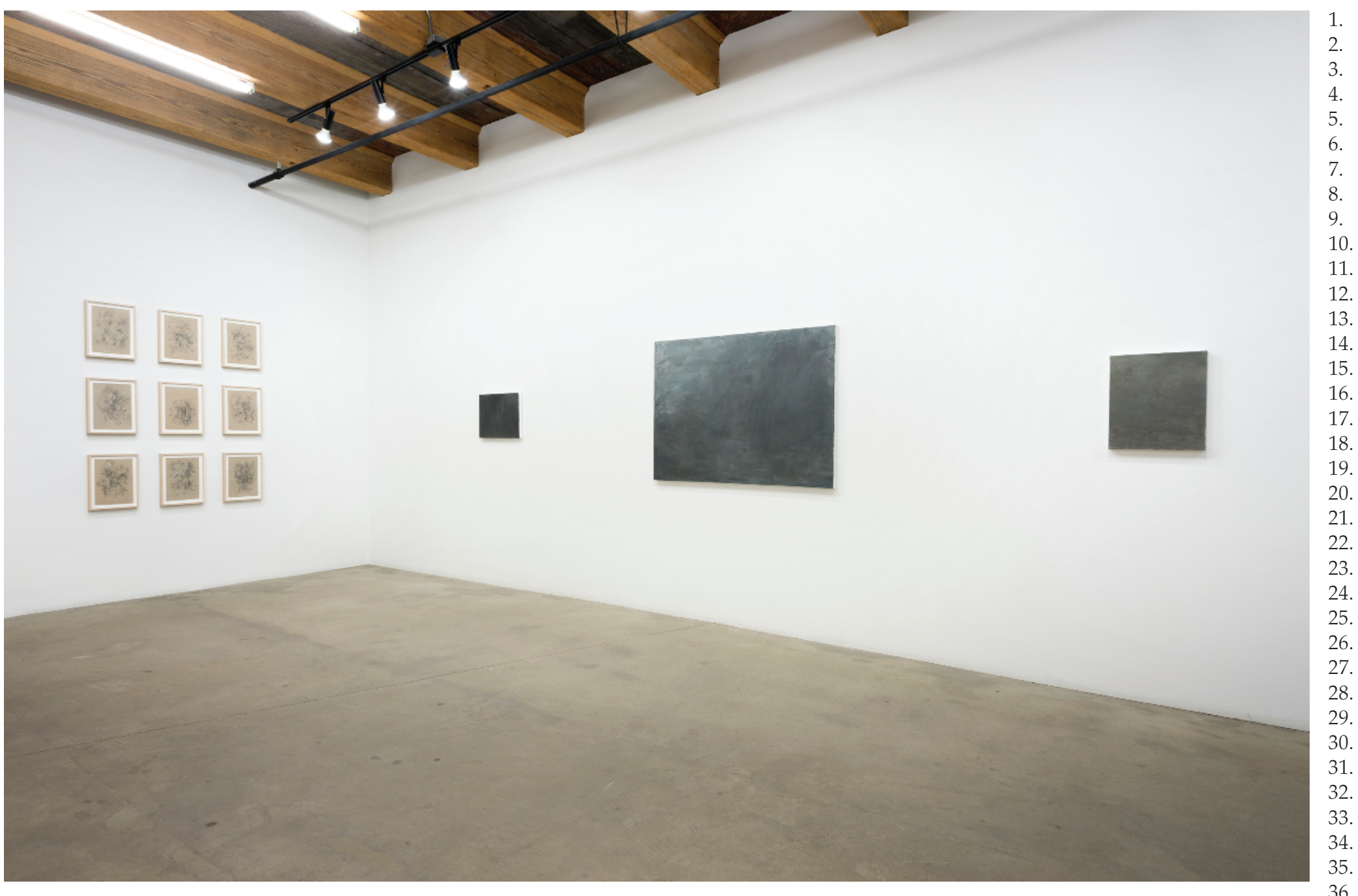

Figure 2: David Schutter (2014), 'What Is Not Clear Is Not French', Installation view; Rhona Hoffman Gallery, April 12 - May 31, 2014, Image: RCH | EKH Art Documentation; courtesy of Rhona Hoffman Gallery. 
1. DS: The paintings that I make are redistributed via the exhibition encounter. After all, the 'originals' . are entirely already present in their own house of the collection in which they live and function, but . to send them out into the world again estranged they are alive in a different way. To me, the act of . forgetting as a painter is to be able to spend time with the works first hand, make their likeness in 5. the studio, and let them go, say, into the ether; it is a release. In other words, to render the works after studying them intimately, is a way of placing them aside. In that adjacency they are maybe more available to me as 'forgotten'. I can set them aside.

CM: Could you say a bit more about the practical terms of the process of 'forgetting' and 'setting aside'? 1. What seems at first a very conscious decision appears to be a very unconscious process.

DS: Mediation is a curious term. I am using a painting as a point of focus, say a Hals portrait. ${ }^{10} \mathrm{I}$ am not interested in being a medium, as in a séance, but rather I am using the Hals portrait as a source. After months of becoming familiar with Hals' hand and brush, though I may invoke the traits 5. of Hals as a painter, I am not interested in speaking through him, like a medium, in an attempt to . embody him as an artist as shaman. I am more interested in the actual surface of his paintings, his 16. techniques, the appearance of things. I to try to move closer, or as close as I can, toward what is a 18. Hals. I have no romantic ambitions to recreate a Hals. What I have is a historical moment before 18. me that gives me a Hals as subject. With it, I can do very little but look at his painting and make a 19. painting in response, from my historical position. This is a mediation, flawed as it may be, so far as 20. I can see from your question. What I do is perhaps a mediation to address the past as a present and 21. uncomfortable entity. I am interested, in this regard, that both the Hals and my painting after it are 22. living in the same world, further complicating relationships to vision and history. For instance, I may 23. be setting aside the Hals painting, or forgetting it, in some phenomenological sense, but I am very much attempting to unearth a discussion on the painting and what it represents. As an example, I made a group of 5 large Hals portraits that were commissioned to Hals by the investors and chief 67. shareholders of the Dutch East India Trading Co (see e.g. Figure 3) To raise a conversation around 28 issues of colonization, the global reach of power, the subjugation of people, and the disproportionate 28. distribution of wealth at this particular time in history is at the nexus of why I chose those particular 30. Hals pictures, located in New York and London. So, the repetition that I employ is not just in the 31. repetition of re-making a painting, but is in the repetition of addressing the representations and 31. histories in the pictures.

CM: Does your work show (in an almost Brechtian way) a reflection on defamiliarization and the malleability of the sign/image? How do you prevent the viewer from becoming too familiar, accustomed to the image, or - conversely - too alienated? Terry Eagleton, for instance, describes Brecht's Alienation Effect as an requires a critical analysis of the link between trace, touch between trace, touch and gesture, and 'ts organic referent' (1993: 231). Individual gesture and the notion of authorship in Schutter's work becomes in particular contested and inevitably reworked

10. Schutter created a body of work 'Glove in Hand' in 2015 (see Figure 3), shown at Aurel Scheible Berlin 2 May $2015-27$ Berlin (2 May 2015-27 June 2015). The work is inspired by five portraits of Dutch merchants by seventeenth-century painter Frans Hals. 


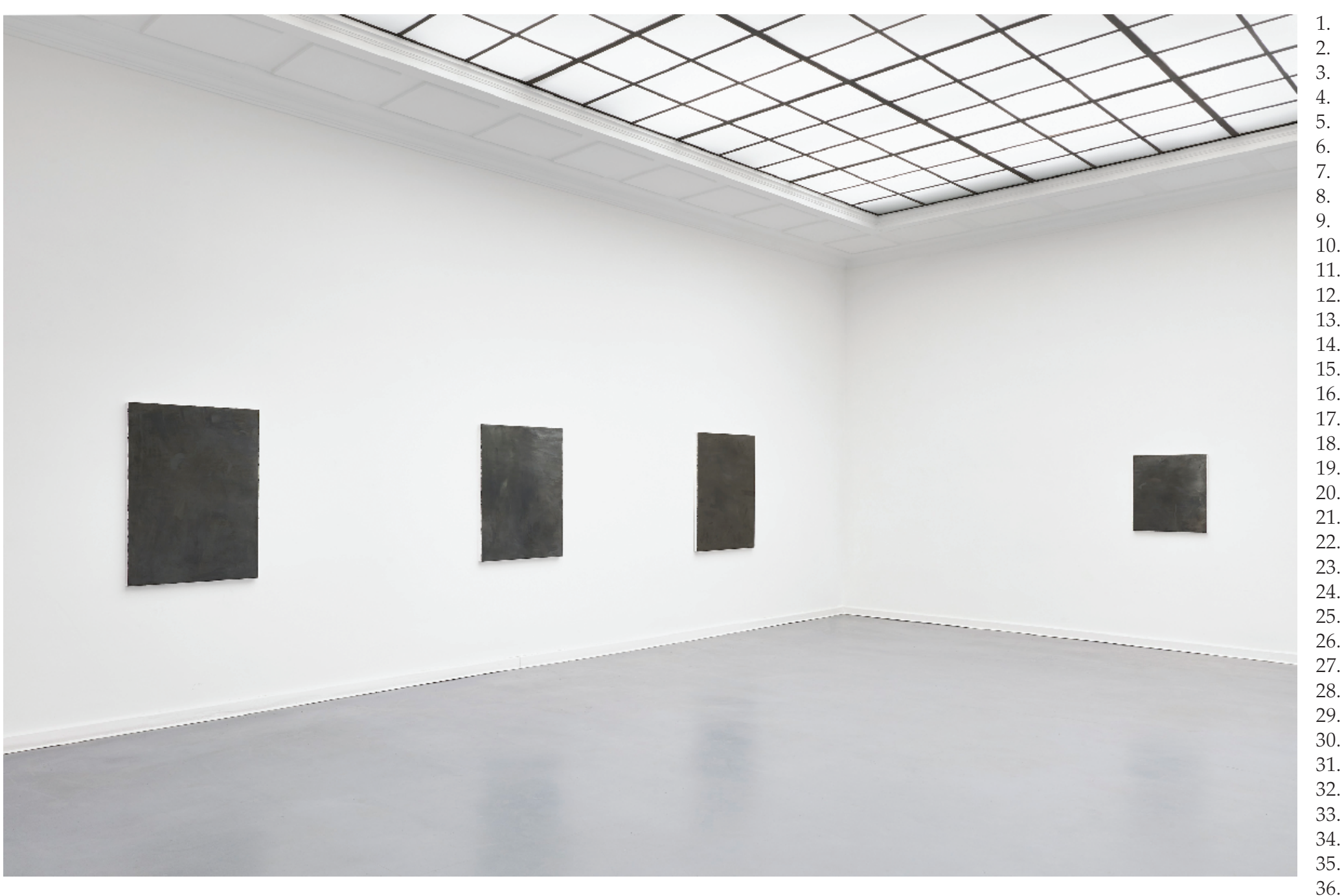

Figure 3: David Schutter (2015), 'Glove in Hand', Installation view, Aurel Scheibler, Berlin, Photo: def image. 
1. 'effect [that] is one of presence and absence together' (1985: 633). Do you recognize in your painting aspects of 'cancelling' as a productive strategy?

DS: I think that your citing here makes sense, I am not so familiar with Eagleton on Brecht, but I can say that absence and presence is a concomitant set that I find productive, as I think on the source picture and my work together as a set. Would that productive dialectic of absence/presence add up to a cancelling? I am not sure. The ontological threads that become frayed in reasoning a way of looking at one of my works is, I hope, productive. But I am not trying to actively cancel anything.

CM: To my understanding, your work seems to respond to a current tendency where a sense of diminished clarity and ambiguity of the image, and interest in the dissolution of the image, can be seen as an attempt to disconnect the image from the world, what could be called an 'imageless truth', abandoning a sense of iconicity (see Figure 4). I would be interested to hear about the ways in which you withdraw and delay the

14. 'consumption' of images in your work, if you think that is the case. Is there a correlation between the delay 16. in the artistic practice and the perception of the audience?

17. DS: Perhaps at this moment we crave an ambiguity from contemporary art because so much of our 18. consumption of visual imagery is based in the explicit. I do not think that by nature, ambiguity is an

19. ultimate power, even in this setting. I am more interested in the strength of paradox. Ambiguity is a

20. valuable trait to suspend or upset circumscribed thought, but as an end, I feel it is over-extended. I

21. would rather use it as a middle ground toward paradox, which I feel is more rich with redress, revi-

22. sion, and new beginnings, no matter how cumbersome these things may be. I am not certain about

23. 'imageless truths'. Or Truth in general. I do not try to degrade the images I work with as sources. I

24. am trying to make 1:1 renderings in one way or another. I recognize that the paintings I make are

25. not interchangeable with the sources, like Pierre Menard's Cervantes, but essentially that is the goal

26. by which I fail. What I live within the studio is the gap that exists, the, not degraded, but, rather the

27. liminal plane of what remains. I do not want to disconnect images from the world, as you say, but I'd

28. rather bring paintings to the fore, as vital ways of seeing in the now, a facing of a historical eye that

29. recognizes our present as a fraught place.

30.

31. CM: I wonder if you can expand on the point about the 'liminal plane' that you mention. In a more literall

32. spatial way liminal planes seem less controlled and regimented. I am thinking, very practically, of the edges

33. of paintings where painters often 'relax' and the unexpected, less controlled brushwork appears.

34.

35. DS: Yes. I am glad you asked this. I don't go about making the pictures with an alpha-omega desire 36. for completion. In other words, I am not a tightrope walker. Many things spill and slip into the 


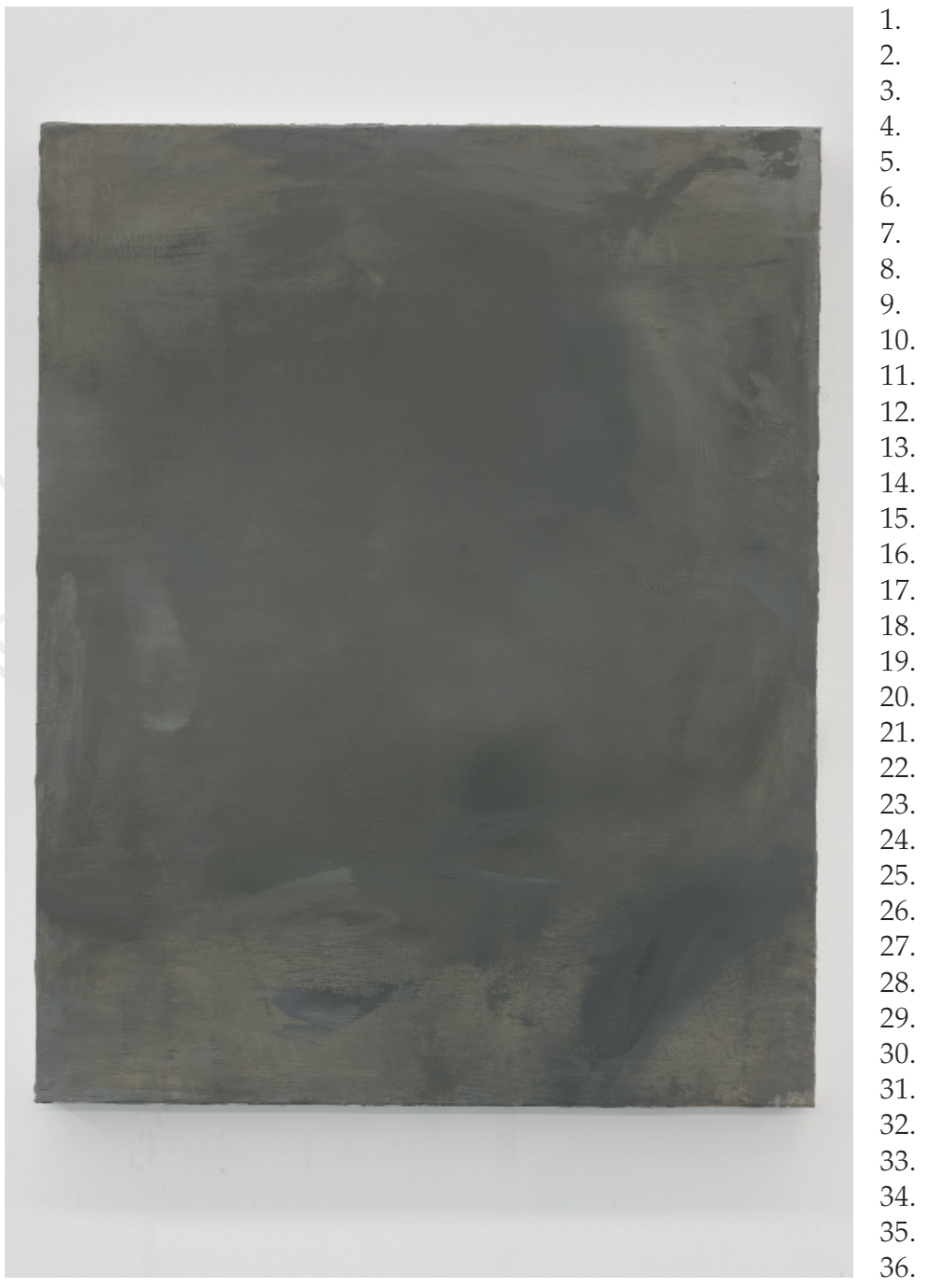

Figure 4: David Schutter (2015), MMA H 636a 2, oil on linen, $80.6 \times 66$ cm, Location: Rose Art Museum, Brandeis, University. Image Credit: James Prinz. 
1. pictures on this liminal plane. For as much as I may want to restrict my focus to only the painting at 2. hand (and its connective source) I always have the uninvited guest slip into the room of the work. 3. That takes many forms which I cannot name here. One painter that I can say is a spectre for me with 4. some regularity is Cezanne. I have never worked with a Cezanne as a source material, but he is leak5. ing through the seams of whatever barrier I may set for before myself.

7. CM: Does the 'obstacle' of not being able to see opens up new possibilities for your work, in both the makingprocess and for the viewer?

DS: There are no obstacles that I intentionally place into play. While I admit that the image or the object of my painting may deny immediate access to see with clarity, I am not intentionally cultivating obfuscation, nor am I interested in a baffling of the eyes of the beholder. I am interested in deadpan presentation and the events that follow. To me, the presentation of illusory space is a parlor trick that questions belief structures. I consider my paintings and drawings to be illusory 4. Works in the conventional sense. However, as you say, 'not being able to see' is important in this 16. regard. Often in the course of making a painting, I feel as if I cannot see clearly a way forward.

17. If an illusory space is made without firm coordinates or clear perspective, then 'not being able to 18. see', as I make the painting, or 'not being able to see' as the viewer on the other end, is a genera19. tive problem. It nullifies projections of what the painting could be and forces an engagement 20. with what it is

26. DS: I actually think that your question on this regard is right on. In fact, I would take that question 27. and make it into a statement, if I had the wildness within me to think that I could harness and 28. work with as material what you describe. I am interested in those very things, but with caution 29. and scepticism. It would be foolish for me to say I want to court the gap of the unrepresentable. 30. Could I say instead that I know those phenomena exists and understand that it is a complex full

31. of wonder and terror, but I can never use this thing as a tangible material as a painter. That is the 32. territory of Frenhofer in de Balzac's Unknown Masterpiece ([1831] 2001). I address what you high-

33. light at a distance and discuss that distance, and my observations from that vantage, in the work 34. I make. These hollowed out spaces you mention, I try to make them full. I can say that, know-

35. ing how paradoxical it sounds - hollowed/full, but still this is in my mind as I work. Space is not 36. empty. 
CM: The figure/ground division seems central to the idea of painting and the transgression of the binary 1 . opposition appears to question the stability of the visual field. I wonder to what extent this plays a role in 2. your work. Furthermore, the 'instability of the mark' (Elkins 1998) in particular seems relevant to some of 3. your recent body of work, including Spolia (2016) (for example, the idea of pretence of likeness). Could your 4. work be interpreted as exploring different degrees of likeness or proximity?

DS: I very much feel that, as you so eloquently state it, much of my work is about likeness and proximity. One must ask then, a likeness to what source, and then too toward a proximity of what location? If Cezanne had the urge to make paintings as heavy and as present as works in the museum (his desired likeness to old master pictures and toward the proximity of the museum world), I might say that though I work with museum pictures as my sources, I would like to make works that speak of not the heaviness of their actual presence and place, but instead toward the imaginary aspects of their criteria. What makes a picture such as these? What are their traits? How are they made? All of these factors inform how they are seen. The museum can be a palliative zone for painting, so I am not desiring to make pictures that feel as if they are bound for this place.

CM: Are you interested in specific paintings or epochs? How would your work process change if you were to respond to contemporary painting?

DS: I am interested, at least in my practice of working with source material, in the age that brackets easel painting from the fifteenth-nineteenth century in western Europe. It is a huge arena. And it will keep me busy for a lifetime. I think that what we have come to define as painterliness in the West comes from this time. I am interested in taking this apart and trying to understand it, as it informs our now. Of course I am taken by other times, other cultures. There are many moments that stir me that are outside my narrow focus. I am more and more interested in what Hans Belting would define as art before art, or the painting of the icon. Equally I am moved by primitive and medieval works that border his definition, and works outside the canon of the West. But for contemporary painting to be a source, no, I have not the interest to use this as my beginning.

CM: To a certain extent through your work you enable the viewer to see the painting from different angle. You also seem to have a strong interest in viewpoints and positions. The multiplicity of views is often associated with sculpture, not so much so with painting. Why is this important in your work?

DS: I am always thinking about this. The feet of the viewer, and the mobility of these feet. To view a painting is a restless activity, either from boredom, intrigue, or connoisseurship. To change perspectives from any or all of these positions is natural. I make many choices in the paintings to coincide with these changing vectors of spectatorship, even my own. I may scumble a green over a red, a 
. green stroked over in dry paint across a luminescent red, so that when the viewer, or I, move laterally before the picture plane of the painting a swift, but flickering change occurs to reveal a momentary blip or shift that is in time and not in the literal material of the paint. In this way, I try to court a difficult duration, or a phenomenal reading that is active. I strive toward what Nietzsche might have wanted when he said he sought an active readership that did not point out his contradictions, but rather embraced them for their latent pregnancy of meaning across contradiction.

CM: 'Living with images' is an important part of your artistic process. I am referring to the fact that you spend extensive periods of time revisiting and observing paintings, in sharp contrast with the rapid recep-

10. tion and distribution of images characteristic of this century. Is the deliberate 'slow' process in the creation or

11. reception of images a reflection on alternative modes of reception of paintings (e.g. in churches)?

DS: I do want a slower reception. I can only hope that it is alternative to the way that we process images now.

David Schutter, born 1974, lives and works in Chicago.

Recent solo exhibitions include Magazzino, Rome (2016), Aurel Scheibler, Berlin (2015); Rhona Hoffman Gallery, Chicago (2014); Reva and David Logan Center for the Arts Chicago (2013); National Galleries of Scotland, Edinburgh (2009-10); Tony Wight Gallery, Chicago (2008-09); Gemäldegalerie, Staatliche Museen zu Berlin (2006). His work has been shown at Documenta 14, Kassel, Germany (2017).

\section{References}

Ammer, M., Hochdörfer, A. and Joselit, D. (2015), Painting 2.0: Expression in the Information Age: Gesture and Spectacle, Eccentric Figuration, Social Networks, London and New York: DelMonico Books.

Bois, Y. A. (1993), Painting as Model, Cambridge, MA: MIT Press.

Bryson, N. (1984), Tradition \& Desire: From David to Delacroix, Cambridge: Cambridge University Press.

30. de Balzac, H. ([1831] 2001), The Unknown Masterpiece, New York: New York Review of Books.

31. Eagleton, T. (1985), 'Brecht and rhetoric', New Literary History, 16:3, pp. 633-38.

32. Elkins, J. (1998), On Pictures and the Words that Fail Them, Cambridge: Cambridge University Press.

33. Elms, A. (2007), 'David Schutter', Art Papers, May/June, p. 59.

35. Enwezor, O. (2008), 'The postcolonial constellation: Contemporary art in a state of permanent tran36. sition', in O.Enwezor, N. Condee and T. Smith (eds), Antinomies of Art and Culture: Modernity, Postmodernity, Contemporaneity, Durham: Duke University Press, pp. 207-234. 
Geimer, P. (2012), 'Painting and atrocity: The Tuymans strategy', in I. Graw, D. Birnbaum and N. 1. Hirsch (eds), Thinking through Painting: Reflexivity and Agency beyond the Canvas, Berlin and New 2. York: Sternberg Press, pp. 15-36.

Gingeras, A. (2005), 'The mnemonic function of the painted image', in The Triumph of Painting: Albert Oehlen, Thomas Scheibitz, Wilhelm Sasnal, Kai Althoff, Dirk Skreber, Franz Ackermann, London: Koenig Books, n.p.

Halvorson, J. (2014), 'David Schutter: The Lingua Franca of Painterliness', Afterall, https://www.afterall.org/online/david-schutter_the-lingua-franca-of-painterliness\#.WPnNi1KZN0c. Accessed April 2017.

Kaneda, S. (1991), 'Painting and its others', Arts Magazine, 65:10, pp. 58-64.

Molon, D. (2007), The instability of memory: David Schutter's paintings after works from the Gemäldegalerie 12 Berlin (exhibition catalogue), Chicago: Museum of Contemporary Art Chicago. 13.

Rancière, J. (2007), The Future of the Image, London: Verso. (2009), The Emancipated Spectator, London:Verso.

Roelstraete, D. (2009) 'The way of the shovel: On the archeological imaginary in art', e-flux, 04, http:/t 16 www.e-flux.com/journal/04/68582/the-way-of-the-shovel-on-the-archeological-imaginary-in- 18. art/. Accessed May 2017.

(2017), 'Keeper of the Art That Kept Him: David Schutter in Conversation with Dieter 20. Roelstraete', Documenta 14, notes and works, http://www.documenta14.de/en/notes-and- 21. works/21168/keeper-of-the-art-that-kept-him. Accessed May 2017.

Schutter, D. (2007), 'After paintings: Working with the museum collection as a contemporary artist', in Reflections by the 16th group of German Chancellor Fellows 2005/2006, Berlin: Alexander von Humboldt Foundation, pp. 115-18.

\section{Suggested citation}

Mieves, C. (2018), "'Towards understanding the nature of history and its limitations": An interview with the American Artist David Schutter', Journal of Contemporary Painting, 4:2, pp. 285-300 doi: 10.1386/jcp.4.2.285_1

\section{Contributor details}

Christian Mieves is a painter and senior lecturer at Wolverhampton School of Art, UK. He received his Ph.D. in Fine Art from the University of Newcastle upon Tyne (UK). Research themes in Mieves' work to date have included the beach and other border spaces as metaphors for semantically 
1. uncertain fields. His paintings have been shown in exhibitions in Germany, Mexico, Spain and the United Kingdom. Recent publications include journal articles on Luc Tuymans, Dana Schutz, Peter Doig and the Beach in Contemporary Art. He has been co-editor of the special edition of the Journal of Visual Art Practice $(9.3,2010)$. He is co-editor of the book Wonder in Contemporary Artistic Practice (Routledge, 2017).

Contact: Wolverhampton School of Art, The George Wallis Building (MK), Molineux Street, Wolverhampton WV1 1DT, UK.

E-mail: christian.mieves@wlv.ac.uk

Christian Mieves has asserted his right under the Copyright, Designs and Patents Act, 1988, to be identified as the author of this work in the format that was submitted to Intellect Ltd.

14.

15.

16.

17.

18.

19.

20.

21.

22.

23.

24.

25 .

26.

27.

28 .

29 . 